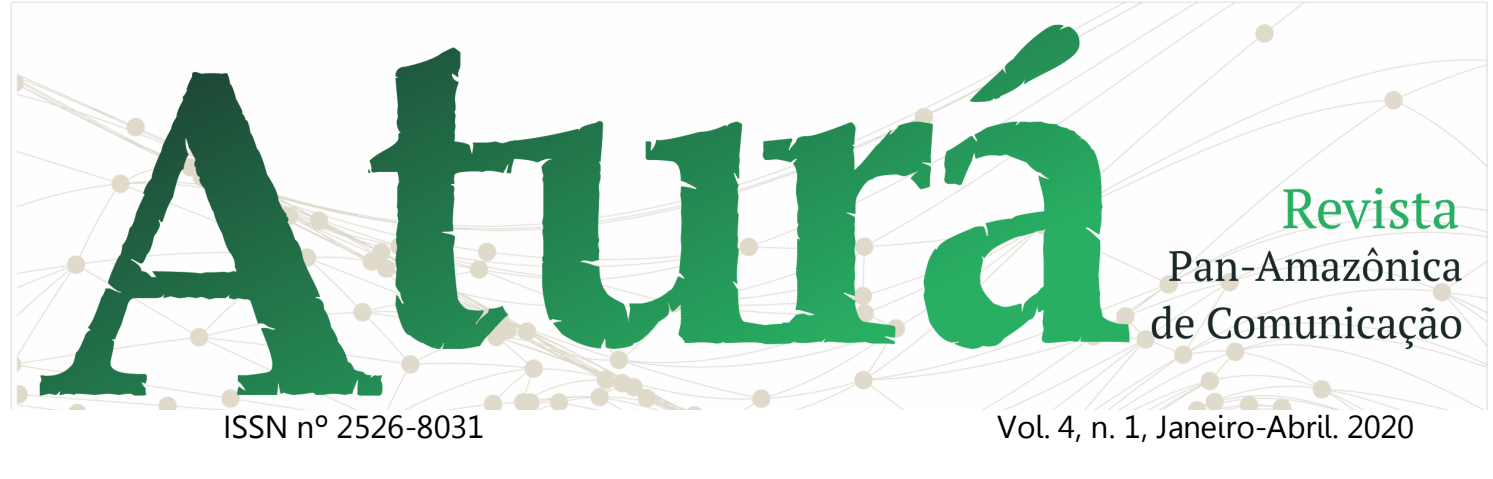

DOI: http://dx.doi.org/10.20873/uft.2526-8031.2020v4n1p235

\title{
DISCURSO DE FACÇÃO E NÃO DE FICÇÃO: a análise do discurso do poder paralelo no Tocantins - Brasil
}

SPEECH OF FACTION AND NOT OF FICTION: the analysis of speech of paraland power in Tocantins - Brazil

DISCURSO DE LA FACCIÓN Y NO DE LA FICCIÓN: el análisis del discurso de paraland power en Tocantins - Brasil

\section{Sthefan Bravin Ponche ${ }^{1,2}$}

\section{RESUMO}

Esta pesquisa de maneira bastante pontual se propõe a mostrar como a Análise do Discurso (AD) é um instrumento indispensável de contribuição no enfrentamento do Estado Democrático de Direito ao Poder Paralelo, mais especificamente ao Primeiro Comando da Capital (PCC) e ao Comando Vermelho (CV), organizações rivais atualmente, que agem dentro e fora dos principais presídios tocantinenses imbuídas também pelas ocultas e micro relações de poder causadas pelo lucro exponencial oriundo do tráfico de drogas e assaltos a instituições financeiras. O objeto em análise é uma carta apócrifa - Salve Geral de 27/08/2016 do PCC - em que os líderes dessa facção no Tocantins, denominados de sintonia final, determinam o rompimento com o CV; isto é, a partir desse salve; tem-se a ruptura entre os principais poderes paralelos instituídos no Tocantins, dando-nos a amalgama para a imersão ao aparato descritivo e interpretativo na linguagem presente que, para muitos, é tida como mera ficção. Deixando, então, patente que o discurso é de facção e não de ficção.

PALAVRAS-CHAVE: Análise do Discurso; Discurso do poder; poder paralelo; Estado do Tocantins.

\footnotetext{
${ }^{1}$ Capitão do Quadro Oficiais Policiais Militares; Mestrando em Análise do Discurso - Letras pela Universidade Federal do Tocantins - UFT; Pós-graduado Latu-Senso pela Universidade Federal do Tocantins em Segurança Pública - UFT (2008); Bacharel em Segurança Pública pela Academia Militar Tiradentes - APMT (2010); Licenciado em Letras Português e suas Literaturas pela Universidade Federal do Espírito Santo - UFES (2007); Bacharel em Direito pela Universidade Estadual do Tocantins - UNITINS (2015); outras especializações profissionais: Curso de Operacional de Rotam na Polícia Militar do Distrito Federal (2013); Curso de Cinotecnia na Polícia Militar de São Paulo (2018). Email: sthefan.bravin@gmail.com.

2 Endereço de contato com os autores (por correio): Universidade Federal do Tocantins. Mestrado em Letras. UFT Campus Palmas - Avenida NS 15, 109 Norte - Plano Diretor Norte - Palmas - TO, 77001-090, Brasil.
} 


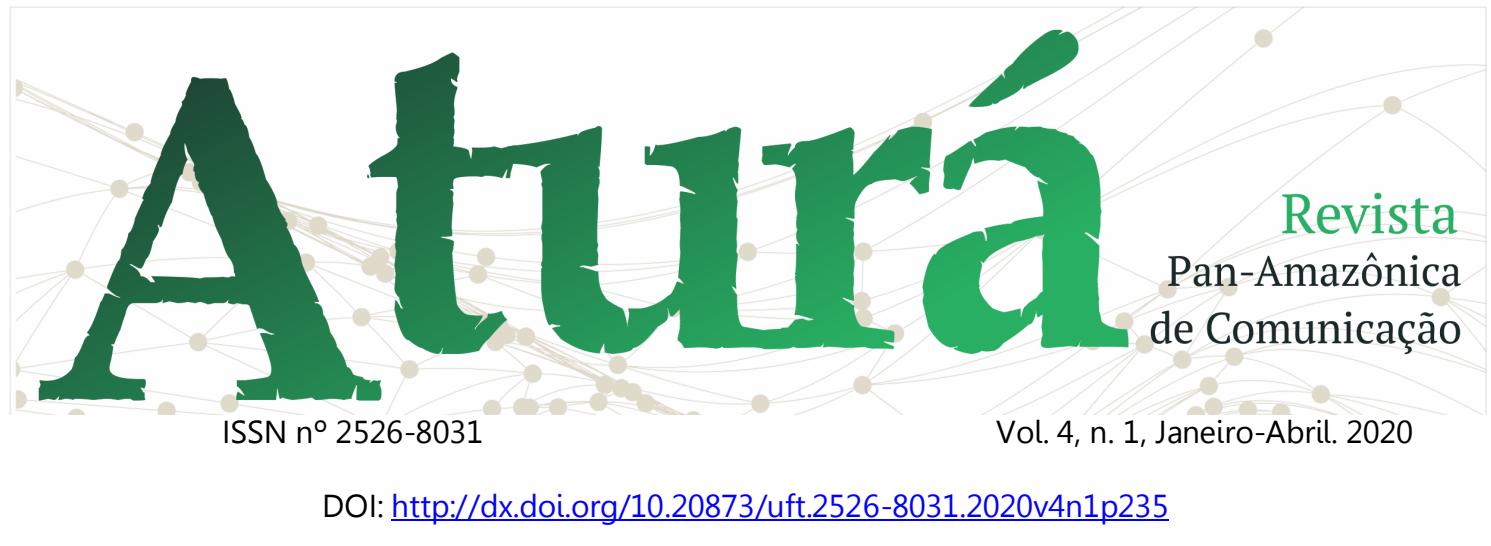

\begin{abstract}
This research in a very punctual way proposes to show how Discourse Analysis (AD) is an indispensable instrument of contribution in confronting the Democratic State of Right to Parallel Power, more specifically to the First Capital Command (PCC) and the Green Command. best (CV), rival organizations nowadays, which act inside and outside the main Tocantins prisons imbued also by the hidden and micro power relations caused by the exponential profit from the drug trade and robberies of financial institutions. The object under analysis is an apocryphal letter - Salve Geral of 27/08/2016 from the PCC - in which the leaders of this faction in Tocantins, de-nominated of final line, determine the break with the $\mathrm{CV}$; that is, from that save; there is a rupture between the main parallel powers established in Tocantins, giving us the amalgamation for immersion in the descriptive and interpretative apparatus in the present language, which, for many, is considered to be mere fiction. Therefore, it is clear that the speech is factional and not fictional.
\end{abstract}

KEYWORDS: Discourse Analysis; Power speech; parallel power; Tocantins State.

\title{
RESUMEN
}

Esta investigación de una manera muy puntual propone mostrar cómo el Análisis del Discurso (AD) es un instrumento indispensable de contribución para enfrentar el Estado Democrático del Derecho al Poder Paralelo, más específicamente al Primer Comando de Capital (PCC) y el Comando Verde. best (CV), organizaciones rivales hoy en día, que actúan dentro y fuera de las principales cárceles de Tocantins imbuidas también por las relaciones ocultas y de micro poder causadas por el beneficio exponencial resultante del tráfico de drogas y los robos de instituciones financieras. El objeto bajo análisis es una carta apócrifa - Salve Geral del 27/08/2016 del PCC - en la cual los líderes de esta facción en Tocantins, des-nominados de la línea final, determinan la ruptura con el CV; es decir, de esa salvación; Existe una ruptura entre los principales poderes paralelos establecidos en Tocantins, lo que nos da la fusión para la inmersión en el aparato descriptivo e interpretativo en el lenguaje actual, que, para muchos, se considera mera ficción. Por lo tanto, está claro que el discurso es fraccional y no ficticio.

PALABRAS CLAVE: Análisis del discurso; Discurso de poder; poder paralelo; Estado de Tocantins.

Recebido em: 12.11.2019. Aceito em: 12.12.2019. Publicado em: 03.01.2020. 


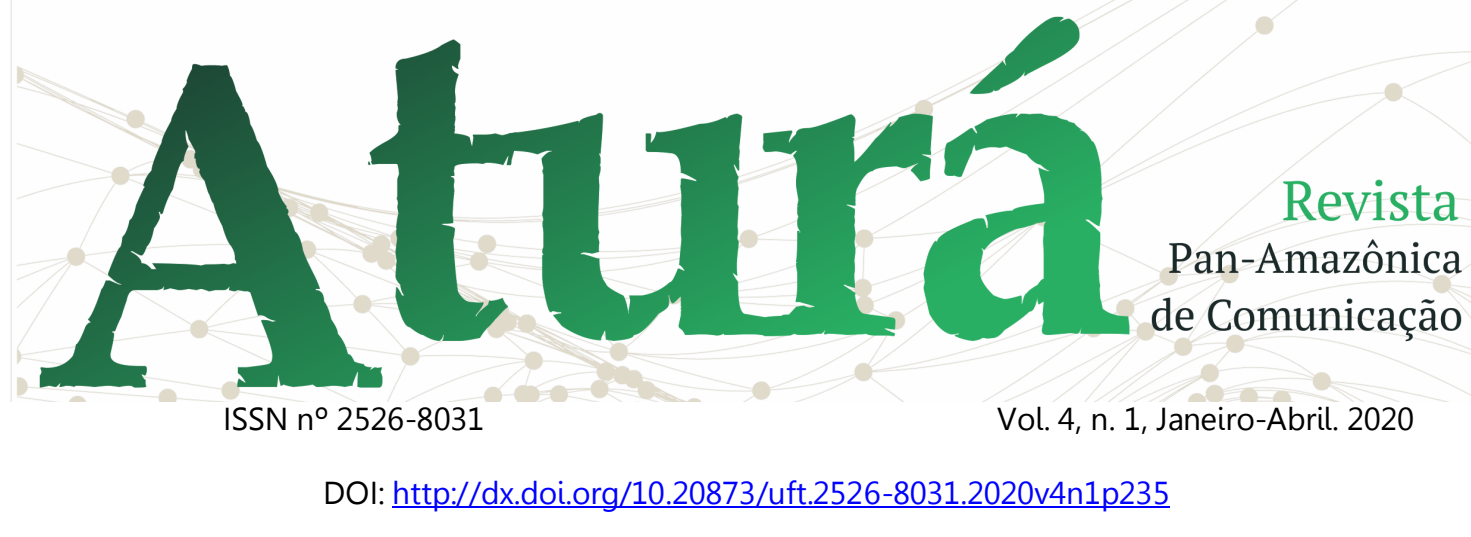

\section{INTRODUÇÃO}

O estudo se alimenta da Análise do Discurso, doravante $A D$, para delinear como o Poder Paralelo se apresenta por meio de produções discursivas, geralmente em forma de cartas apócrifas - Salves Gerais ${ }^{3}$ - escritas pelos seus líderes, os quais são denominados genericamente de Sintonia Final ${ }^{4}$; sendo esse Poder Paralelo formado por organizações criminosas que, neste ensaio, limitar-se-á ao Primeiro Comando da Capital (PCC) e ao Comando Vermelho (CV), maiores organizações criminosas do País e mais significativas no Estado do Tocantins; tanto dentro, quanto fora dos principais presídios estaduais.

O objeto em análise será o Salve Geral de 28/08/2016, o qual traz a determinação do(s) líder(es) do PCC em Palmas-Tocantins para a ruptura com o outra facção criminosa a fim de que o ideal de união para resistir ao Aparelho Repressivo de Estado(ARE), Althusser(1970), principalmente nos presídios passe a ser coadjuvante e que o mercado do tráfico de drogas e de armas, assim como assaltos às instituições financeiras, ou qualquer outra relação comercial entre elas seja rompida em prol da ideologia capitalista do PCC.

Metodologicamente a análise do corpus em tela direciona para uma pesquisa de cunho documental, subsidiada pela pesquisa qualitativa devido ao grupo estudado; no caso, o discurso do(s) membro(s) do PCC. Sem embargo, a Análise do Discurso imbricada os inacabados propósitos de seu criador faz-se refletir, também, que "[...] Em AD não se fala em metodologia pronta, formada." Marques (2011, p.71). Isto é, a AD encontra-se com suas vias metodológicas em pavimentação. Ou ainda, os métodos hão de evoluir na medida em que a $A D$ ascender à maturidade, uma vez que sua precocidade existencial ainda é um terreno fértil para criações inclusive no campo metodológico.

Quando trazemos o pensamento a Eni Orlandi, a pesquisadora ensina também que:

Há uma passagem inicial fundamental que é a que se faz entre a superfície linguística (o material de linguagem bruto coletado, tal como existe) e o objeto discursivo, este sendo definido pelo fato de que o corpus já recebeu um primeiro tratamento de análise superficial, feito em uma

\footnotetext{
${ }^{3}$ Salve Geral - determinação da cúpula criminosa de uma dada facção;

${ }^{4}$ Sintonia Final - líder(es) de organização criminosa local, regional e/ou nacional detentor das tomadas de decisões.
} 


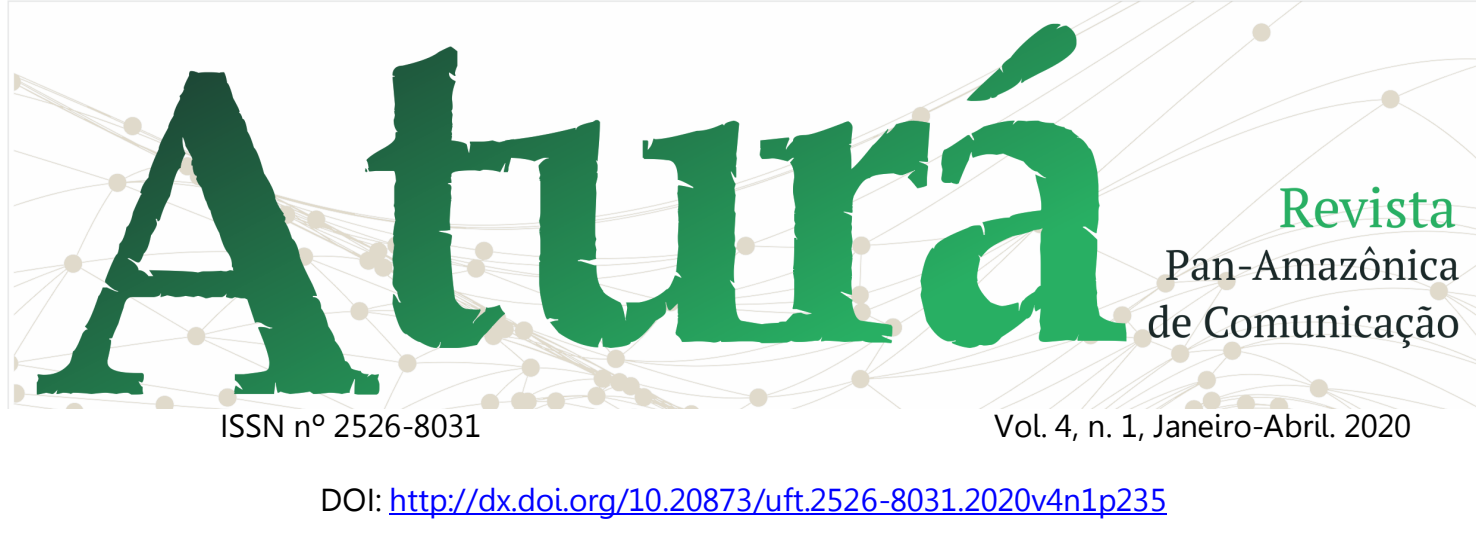

primeira instância, pelo analista, e já encontra desuperficialidade.

2. DESENVOLVIMENTO

Em que consiste esse processo de de-superficialização? Justamente na análise do que chamamos materialidade linguística: o como se diz, o quem diz, em que circunstâncias. Isto é, naquilo que se mostra em sua sintaxe e enquanto processo de enunciação (em que o sujeito se marca no que diz), fornecendo-nos pistas para compreendermos o modo como o discurso que pesquisamos se textualiza.[...] (ORLANDI, 2007, p.65)

Tal ensinamento por parte dessa expoente brasileira também há de ser considerado como procedimento metodológico indispensável para se atingir o processo discursivo demandado no objeto que ora apresentamos.

Descartar a transcrição do objeto foi primar pelo rigor científico, por se tratar de uma pesquisa documental. E a conquista do objeto adveio da formalização e do cumprimento de todos os requisitos por meio de expediente oficial à Secretaria de Cidadania e Justiça do Estado do Tocantins e de seu deferimento para que a pesquisa fosse realizada em prol do avanço dessa área de conhecimento.

Figura 01 - Salve Geral da Sintonia Final 


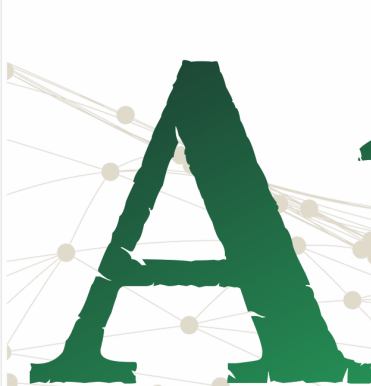

ISSN n² 2526-8031

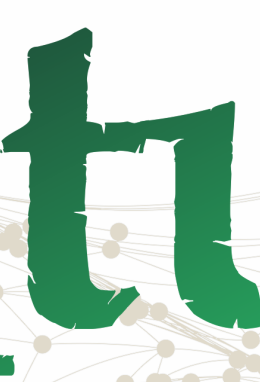

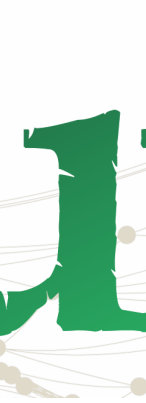

1rá

.

DOI: $\underline{\text { http://dx.doi.org/10.20873/uft.2526-8031.2020v4n1p235 }}$
Revista

Pan-Amazônica

de Comunicação

Vol. 4, n. 1, Janeiro-Abril. 2020

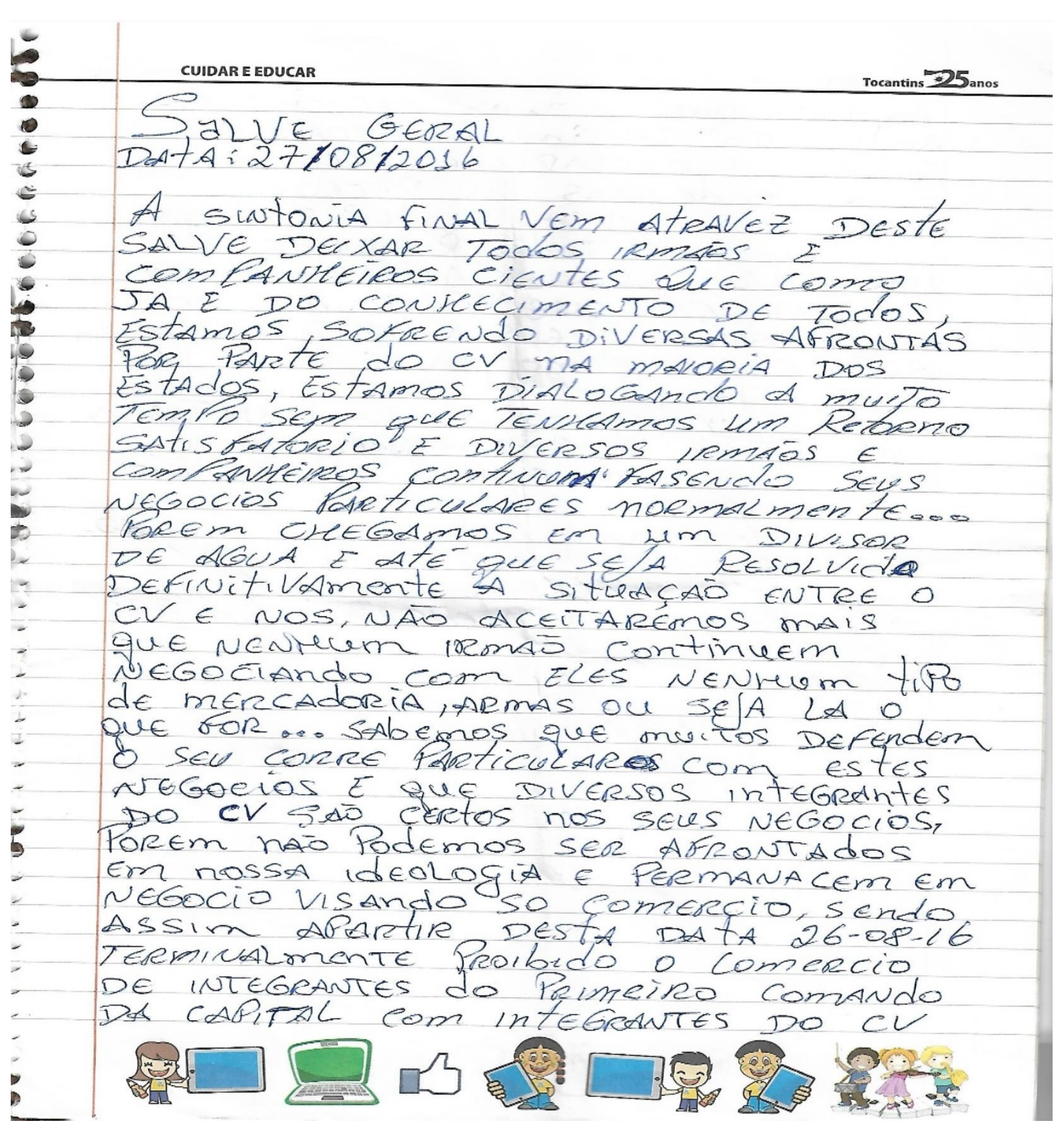




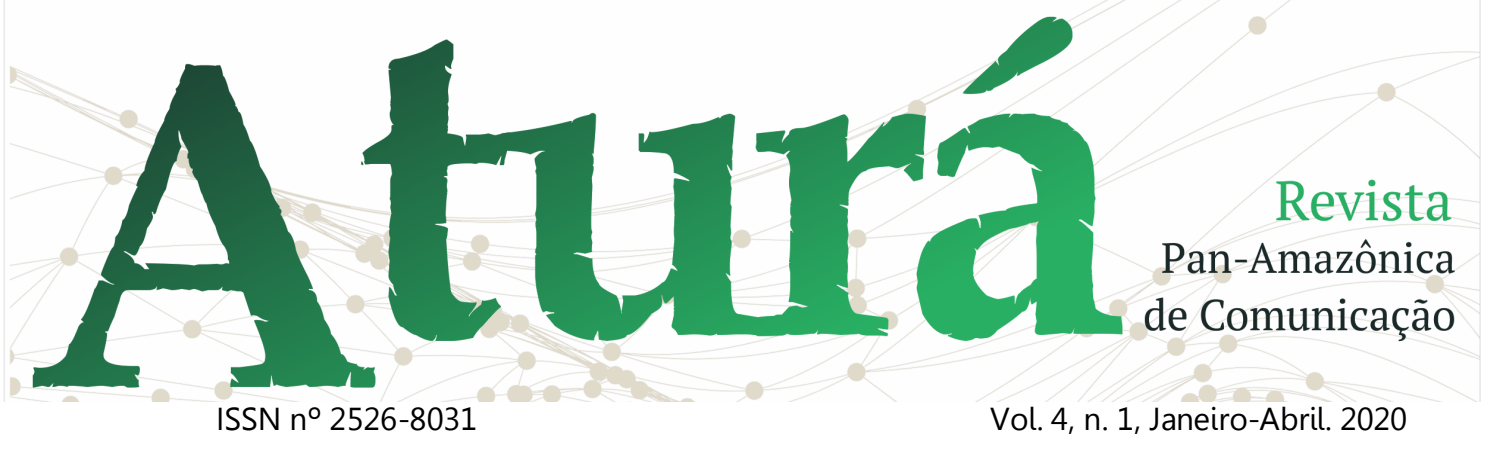

DOI: http://dx.doi.org/10.20873/uft.2526-8031.2020v4n1p235

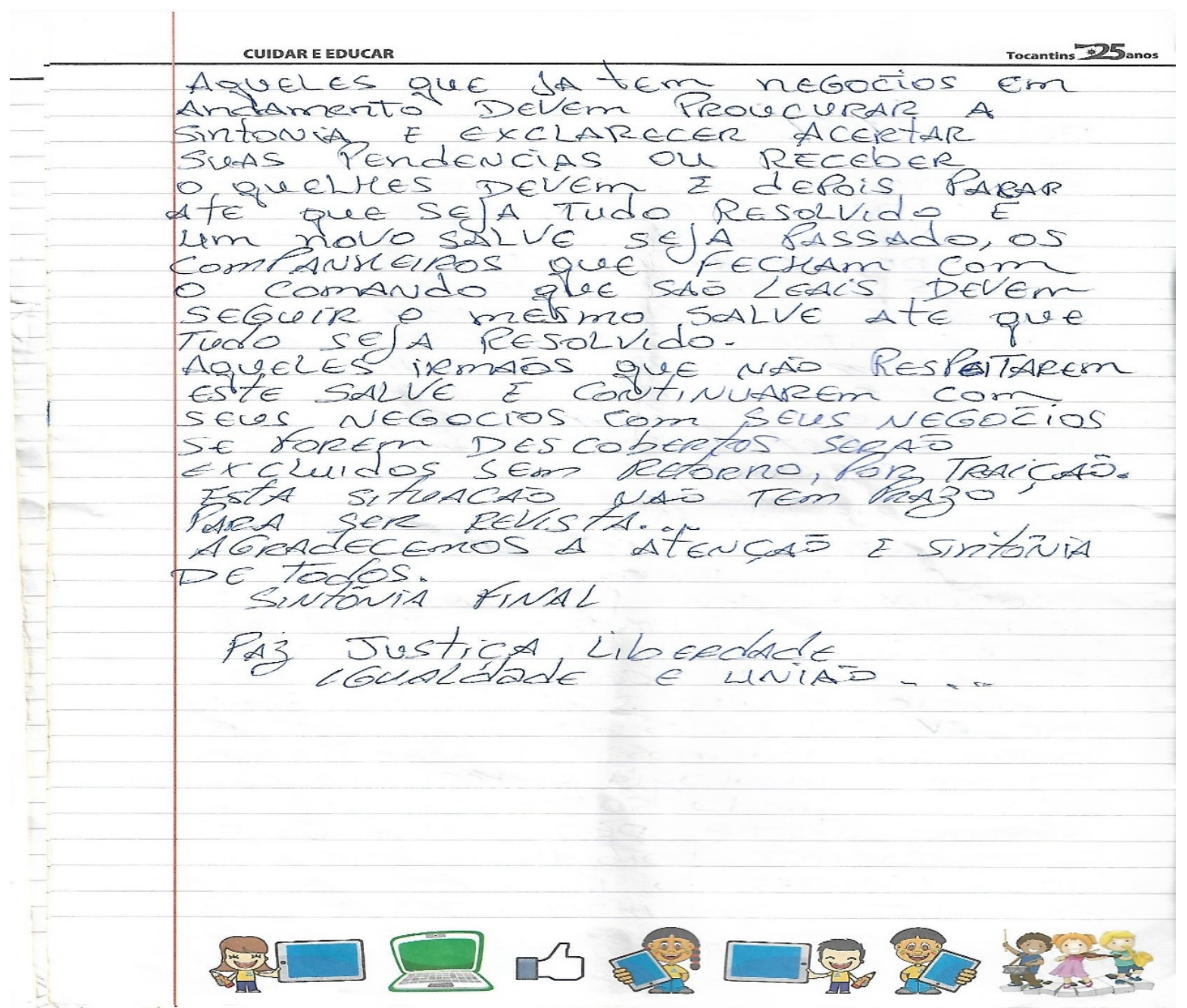

Fonte: Secretaria de Cidadania e Justiça do Tocantins.

Preliminarmente cabe pontuar que ainda que tentássemos esgotar a análise do objeto em questão iniciaríamos um caminho sem volta. O que tentaremos percorrer, como dito outrora, é que o Poder Paralelo existe no Estado do Tocantins, isso é patente, e seu discurso não pode e não deve ser encarado como mera ficção consoante fora feito pelo então secretário de Segurança Pública de São Paulo nos idos de 1997; quando, em entrevista à Folha de São Paulo declarou: "[O PCC] É uma ficção. Uma bobagem. Estou absolutamente convencido disso. Sou Secretário há quase dois anos e nunca vi qualquer manifestação 


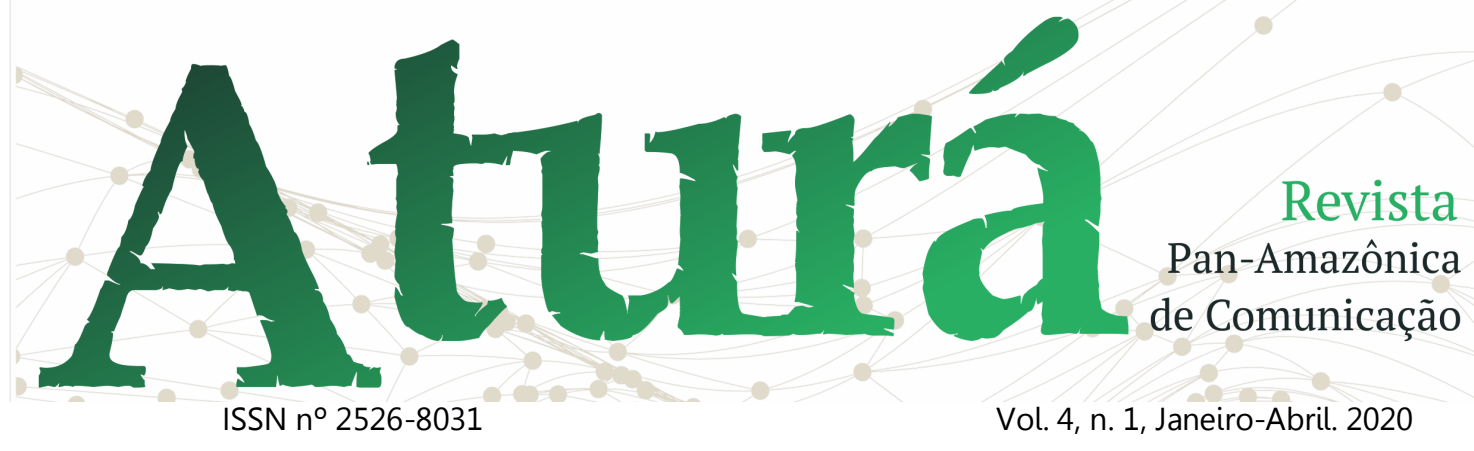

DOI: http://dx.doi.org/10.20873/uft.2526-8031.2020v4n1p235

desse grupo." Manso e Dias (2019, p. 89). E para que esse percurso seja realizado de maneira menos sinuoso, iniciá-lo-emos pelo fim; pela ideais do PCC.

Mas antes da imersão no corpus propriamente dito, iremos nos valer de duas pontuais considerações, são elas: a valoração do objeto escolhido e a perspectiva teórica francesa. A primeira foi apregoada por Dominique Maingueneau da seguinte forma:

O caráter fundamentalmente crítico dos estudos de discurso se manifesta também por meio de seu poder dessacralizador. De fato, um discursivista se recusa a considerar que certas áreas da produção verbal poderiam não ser objetos de estudo legítimos. Uma análise dos grafites, das conversas, dos romances pornográficos, dos panfletos publicitários ou dos textos administrativos é tão legítima quanto uma análise do discurso filosófico ou literário: quaisquer que sejam suas diferenças de prestígios, pode-se distribuí-los num mesmo espaço, apreendê-los por meio dos mesmos conceitos, pensar suas relações na unidade do interdiscurso. (MAINGUENEAU, 2017, p. 60)

Ou seja, o preconceituar a análise de um dado corpus é o mesmo que reduzir o intelecto à insignificância. É comparar o incomparável. É desconstruir. É se fechar. É, por fim, perpetuar as diferenças. Então como não valorar o quilate discursivo Poder Paralelo? Textos possuidores de uma formação discursiva imensurável para a realidade atual.

Quanto à questão da perspectiva teórica francesa, a professora Helena H. Nagamine Brandão descreve que :

Preconizado, assim, um quadro teórico que alie o linguístico ao sócio-histórico, na $A D$, dois conceitos tornam-se nucleares: o de ideologia e o de discurso. As duas grandes vertentes que vão influenciar a corrente francesa de $A D$ são, do lado da ideologia, os conceitos de Althusser e, do lado do discurso, as ideias de Foucault. É sob a influência dos trabalhos desses dois teóricos que Pêcheux, um dos estudiosos mais profícuos da $A D$, elabora os seus conceitos. De Althusser, a influência mais direta se faz a partir de seu trabalho sobre os aparelhos ideológicos de Estado na conceituação do termo "formação ideológica". E será da Arqueologia do saberque Pêcheux extrairá a expressão "formação discursiva", da qual a AD se apropriará, submetendoa a um trabalho específico. (BRANDÃO, 2017, p.18, grifo do autor)

Isto quer dizer que o criador da $A D$ teve influências diretas desses dois expoentes e a partir de suas concepções iniciamos a análise propriamente dita.

O que nos faz lembrar os ideais $P A Z$, JUSTIÇA, LIBERDADE, IGUALDADE E UNIÃO? Sem muito esforço, tem-se o pensamento remetido de pronto à Revolução Francesa, um interdiscurso que aponta para a variável história, a qual foi determinante na construção da 


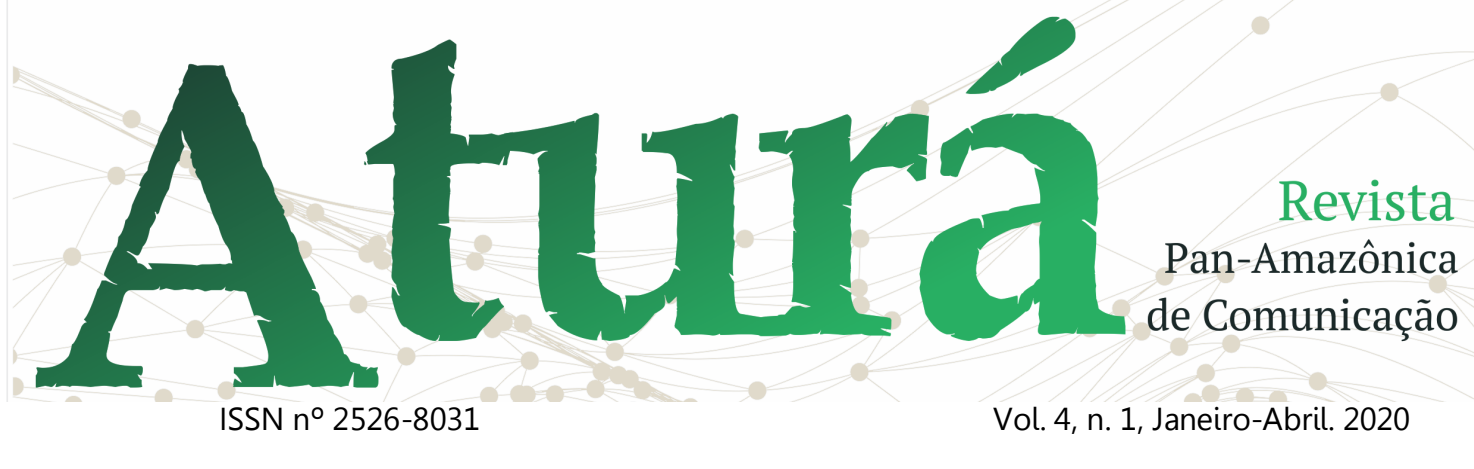

DOI: http://dx.doi.org/10.20873/uft.2526-8031.2020v4n1p235

AD. Movimento que se opunha essencialmente aos pensamentos absolutistas. A França foi palco do movimento que trouxe o lema de Liberdade, Igualdade e Fraternidade a fim de se opor ao Absolutismo que tinha a figura do imperador como detentor máximo do poder no Estado. A partir do lluminismo, a ideia dos direitos humanos floresce de maneira mais contundente. Neste ínterim, o que faz o PCC querer PAZ? Qual é a guerra em questão? A guerra é contra o Estado opressor como assevera Althusser (1970, p.31)? "Estado é uma máquina de repressão que, permite às classes dominantes assegurar a sua dominação sobre a classe operária para a submeter ao processo de extorsão da mais-valia.". Ou a guerra é contra as outras organizações tal como o CV? Como será visto, essa exploração existe e se apresenta muito mais feroz ao ponto de causar a ruptura entre as organizações. Neste ponto, não há como duvidar de que a guerra primária do PCC advém contra O Estado, opressor por meio dos seus Aparelhos Repressivos de Estado, que detêm o monopólio da força contra os faccionados. E no segundo momento, não há como refutar também que existe uma guerra entre elas em busca de mercado consumidor para o tráfico de drogas que promove um lucro vertiginoso à sintonia final. Quando conclamam a JUSTIÇA, teríamos como exemplo uma argumentação perene difundida por Cessare Beccaria:

\begin{abstract}
Um homem acusado, aprisionado, julgado e absolvido não deve ser marcado pela infâmia. Entre os romanos, vimos que muitos acusados de grandes crimes, e posteriormente declarados inocentes, eram respeitados pelo povo e homenageados com empregos no Estado. Mas por que o destino de um inocente é tão diferente em nossa época? É porque o atual sistema de leis penais apresenta em nossas mentes a ideia de poder, em vez de justiça; é porque o condenado e o acusado são jogados, indiscriminadamente, na mesma prisão; porque a prisão é mais uma punição do que uma forma de reter o acusado e porque as forças internas que defendem as leis e as forças externas que defendem o trono e o reino são separadas, quando deveriam ser unidas. (BECCARIA, 2012, p. 91).
\end{abstract}

Qual a expectativa de um jovem conquistar um bom emprego no Brasil depois de preso por tráfico de drogas e cumprir a pena que the fora imposta pelo Estado? Principalmente empregos públicos? A chance mensurada, infelizmente, se aproxima de zero. Pois com a solicitação de antecedentes criminais a chance será retornar para os ruas e vender drogas novamente ou, se tiver muita sorte, terá um trabalho informal sem perspectiva de 


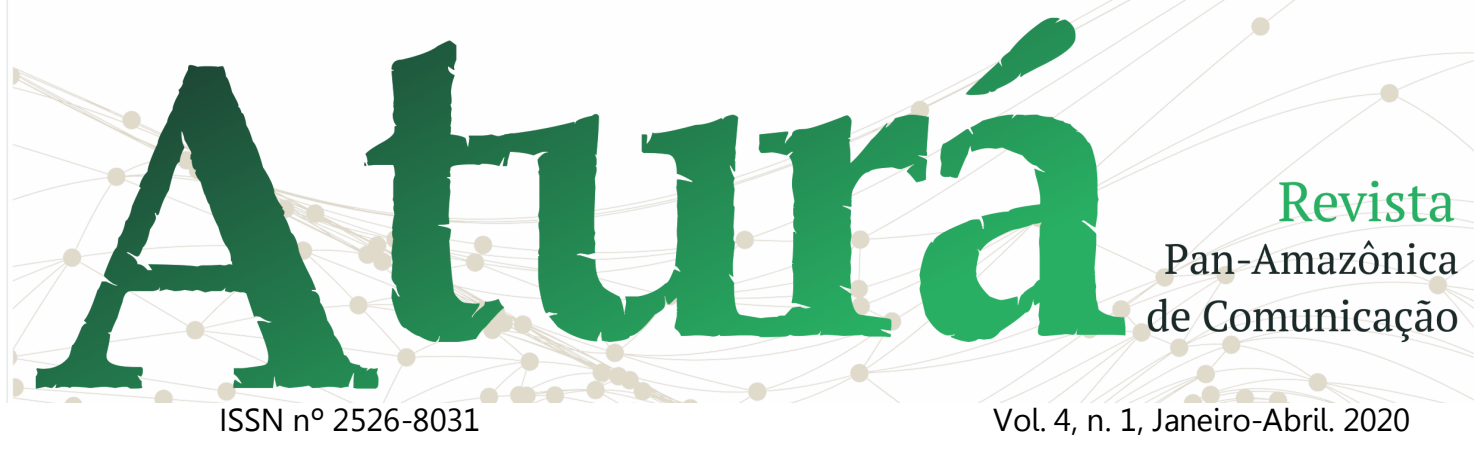

DOI: http://dx.doi.org/10.20873/uft.2526-8031.2020v4n1p235

uma aposentadoria digna quando perder suas forças.

Quanto à LIBERDADE, à IGUALDADE e à UNIÃO conclamada pelo PCC, vamos nos ater preliminarmente ao que apregoa o artigo I da Declaração Universal dos Direitos Humanos: "Todos os seres humanos nascem livres e iguais em dignidade e direitos. São dotados de razão e consciência e devem agir em relação uns aos outros com espírito de fraternidade." (VADEMECUM SARAIVA, 2019, p.1180, grifo nosso).

Qual a liberdade de um escravo do tráfico de drogas hoje e daquele do século XVIII neste mesmo país? "A liberdade desses guerreiros não é a da tolerância e da igualdade para todos; é uma liberdade que só pode se exercer mediante a dominação. Isto quer dizer que, longe de ser uma liberdade de respeito, é uma liberdade de ferocidade". (FOUCAULT, 2010, p.124)

O simplório questionamento se o Estado Democrático de Direito trata a liberdade de maneira igual quando há união de valores na execução das medidas penais de restrição de liberdade já responderia à ideologia do Poder Paralelo. Ainda que o povo brasileiro tenha assistido à prisão de muitos políticos nos últimos anos, ainda não demonstra, nem de longe, a igualdade angariada. Daí a união entre os faccionados para se lutar por esses ideais.

Michel Foucault em Vigiar e Punir retrata sobre outro prisma a questão:

O poder sobre o corpo, por outro lado, tampouco deixou de existir totalmente até meados do século XIX. Sem dúvida, a pena não mais se centralizava no suplício como técnica de sofrimento; tomou como objeto a perda de um bem ou de um direito. Porém castigos como trabalhos forçados ou prisão - privação pura e simples da liberdade - nunca funcionaram sem certos complementos punitivos referentes ao corpo: redução alimentar, privação sexual, expiação física, masmorra. Consequências não tencionadas mas inevitáveis da própria prisão? Na realidade, a prisão, nos seus dispositivos mais explícitos, sempre aplicou certas medidas de sofrimento físico. A crítica ao sistema penitenciário, na primeira metade do século XIX (a prisão não é bastante punitiva: em suma, os detentos têm menos fome, menos frio e privações que muitos pobres ou operários), indica um postulado que jamais foi efetivamente levantado: é justo que o condenado sofra mais que os outros homens? (FOUCAULT, 1999, p. 19)

O lugar onde os condenados brasileiros, em sua maioria, comprem suas penas são dignos? ressocializam? Ou passaram a ser o centro de violação dos direitos humanos? Qual a revolta estimada de um detento que já foi tão vilipendiado por ter 


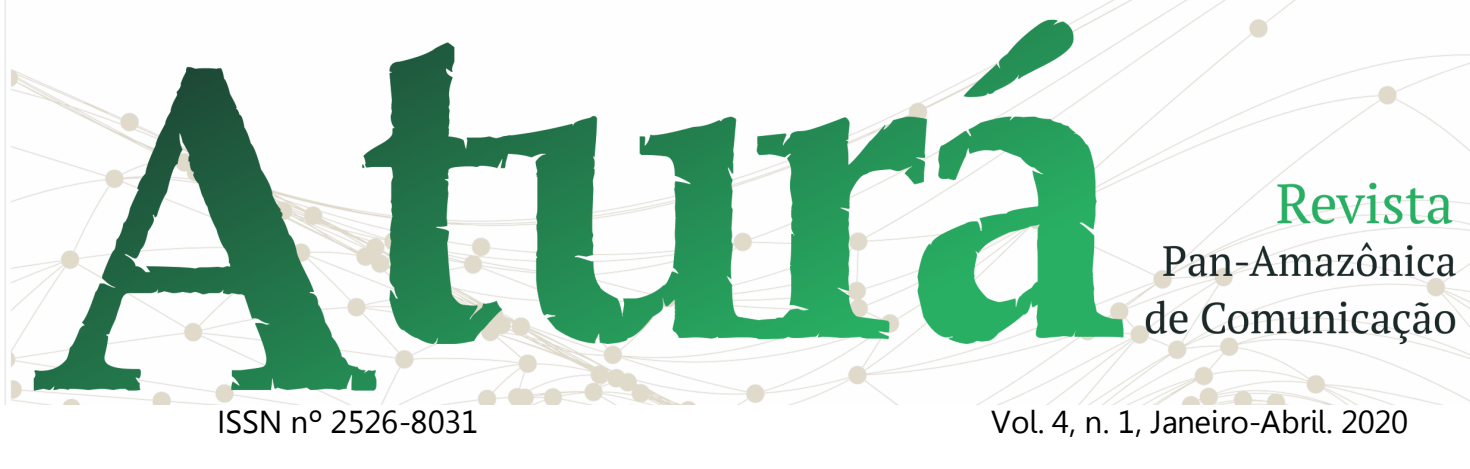

DOI: http://dx.doi.org/10.20873/uft.2526-8031.2020v4n1p235

seus direitos básicos burlados pelo Estado quando estava fora das grades?

Se o Estado não cumpre com o que está em sua carta máxima, o Poder Paralelo edita suas próprias cartas e seu tribunal do crime dentro e fora das prisões. Analogamente

Parece-me que não devemos partir da forma do tribunal e perguntar como e em que condições pode haver um tribunal popular, e sim partir da justiça popular, dos atos de justiça popular e perguntar que lugar pode aí ocupar um tribunal. É preciso se perguntar se esses atos de justiça popular podem ou não se coadunar com a forma de um trinunal. A minha hipótese é que o tribunal não é a expressão natural da justiça popular mas, pelo contrário, tem por função histórica reduzi-la, dominá-la, sufocá-la, reinscrevendo-a no interior de instituições características do aparelho de Estado. (FOUCAULT, 2006, p.39)

A Constituição Federal de 1988 apregoa em seu artigo $3^{\circ}$ os seguintes objetivos:

Art. $3^{\circ}$ Constituem objetivos fundamentais da República Federativa do Brasil:

I - construir uma sociedade livre, justa e solidária,

II - garantir o desenvolvimento nacional;

III - erradicar a pobreza e a marginalização e reduzir as desigualdades sociais e regionais; IV - promover o bem de todos, sem preconceitos de origem, raça, sexo, cor, idade e quaisquer outras formas de discriminação. (Disponível em: <http://www.planalto.gov.br/ccivil 03/constituicao/constituicao.htm>, acessado em: 03 de dez 2019, grifo nosso).
Se construir uma sociedade livre, justa e solidária é o objetivo da República, o do Poder Paralelo não está distante desse propósito respeitadas as devidas proporções dos seus membros. E é assim que a $A D$ se apresenta como instrumento indispensável no auxílio ao enfrentamento ao poder paralelo, pois:

No discurso é onde residem os sentidos atravessados pela história, se encontram as constrições de força e o embate ideológico. Sendo o texto a efetivação linguística da qual se valem os sujeitos em suas práticas discursivas. É também no discurso que estão as múltiplas interpretações margeadas pelo texto e, consequentemente, as leituras dessas. Se o texto é uma unidade de sentido estruturado linguisticamente, o discurso é a dispersão e cerceamentos dos sentidos socialmente. $\mathrm{O}$ uso de um implica necessariamente o do outro.[...](SOARES, 2018, p.83)

O discurso existente no salve é inexoralvelmente atravessado por grande parte da história que os constitucionalistas se alicerçaram para a composição da carta magna de 1988; ou seja, nos ideais positivistas. Então, ao que se evidencia, o texto constitucional não está distante do discurso da sintonia final. As interpreações do discurso são margeadas pelo texto que deveria libertar os iguais nas suas igualdades e não nas desigualdades evidenciadas. 


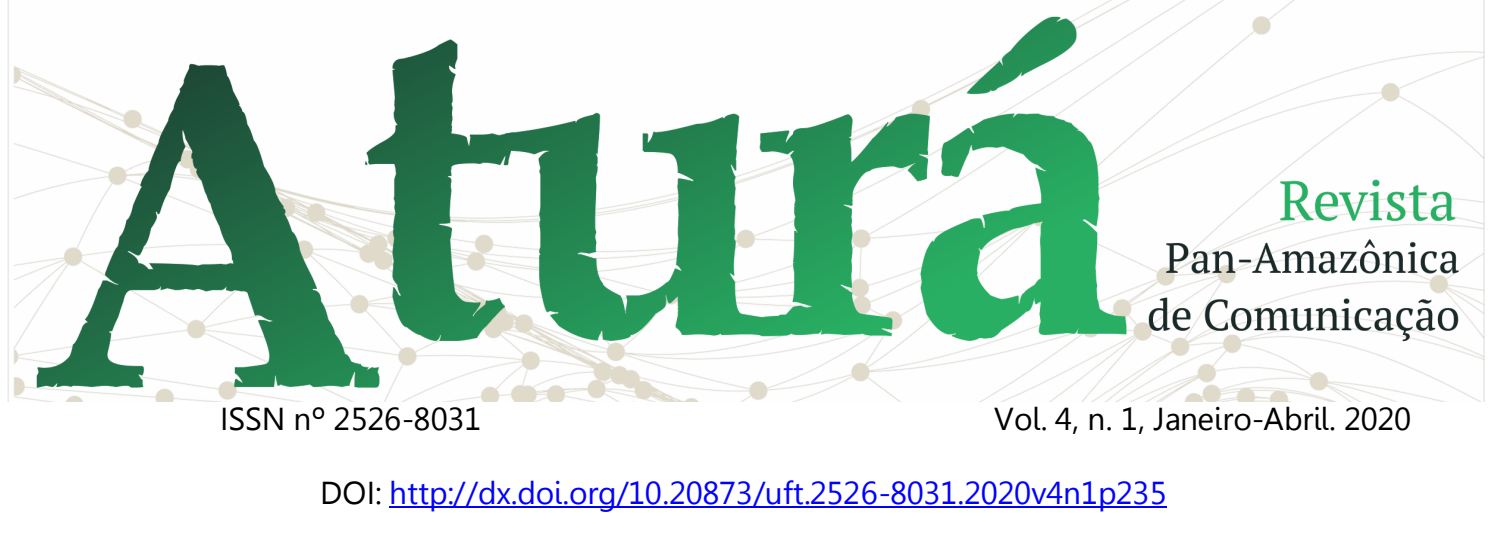

Sem que se despreze os conflitos entre as forças coexistentes, há de se considerar que a ruptura entre as faç̧ões favoresse ao Estado Democrático de Direito, pois as ações do Poder Paralelo são divididas, ou ainda melhor, direcionadas para outros pontos que não para ele. E é assim que a Análise do Discurso de maneira estratégica em meio as micro relações de poder se estabele.

Neste ponto do estudo, daremos atenção as propriedades do sujeito e suas representações no discurso. Lembrando que o discurso é a materialização ideológica e a ideologia revela a faceta do sujeito, ainda que possuidor da preservação identitária como é o caso em tela, fica aqui o saimento de que o discurso tem um viés imperativo e se estabelece no tempo, uma vez que estará em vigor até que outro Salve seja exarado. E isso só se estabelece por meio de uma unidade organizada hierarquicamente.

E porque sua fala é produzida a partir de um determinado lugar e de um determinado tempo, à concepção de um sujeito histórico articula-se outra noção fundamental: a de um sujeito ideológico. Sua fala é um recorte das representações de um tempo histórico e de um espaço social. Dessa forma, como ser projetado num espaço e num tempo orientado socialmente, o sujeito situa o seu

discurso em relação aos discursos do outro.(BRANDÃO, 2017, p.59)

Logo o sujeito apócrifo revela que o discurso é de autoridade por meio das determinações claramente encontradas no corpus e a consequência ao descumprimento é a exclusão por traição. O sujeito, então, molda seu discurso para o devido lugar que ocupa na escala do crime. Demonstração cristalina de que o tribunal do crime existe, tem suas leis e suas sanções impostas. Outrossim, a demonstração da organização do Poder Paralelo e da forte hierarquia é a determinação da ruptura com as relações comerciais, afetando diretamente as famílias que sobrevivem do tráfico de drogas, tráfico de armas e dos roubos. Na omissão do Estado, o Poder Paralelo impõe suas micro relações de poder subsidiado pelo açoite do capital.

\section{CONSIDERAÇÕES FINAIS}

É irrefutável que o Poder Paralelo está presente no Estado do Tocantins; e tratar como mera ficção bem como o Secretário de Segurança Pública do Estado de São Paulo fez nos idos de 1997 por meio da tentativa de si- 


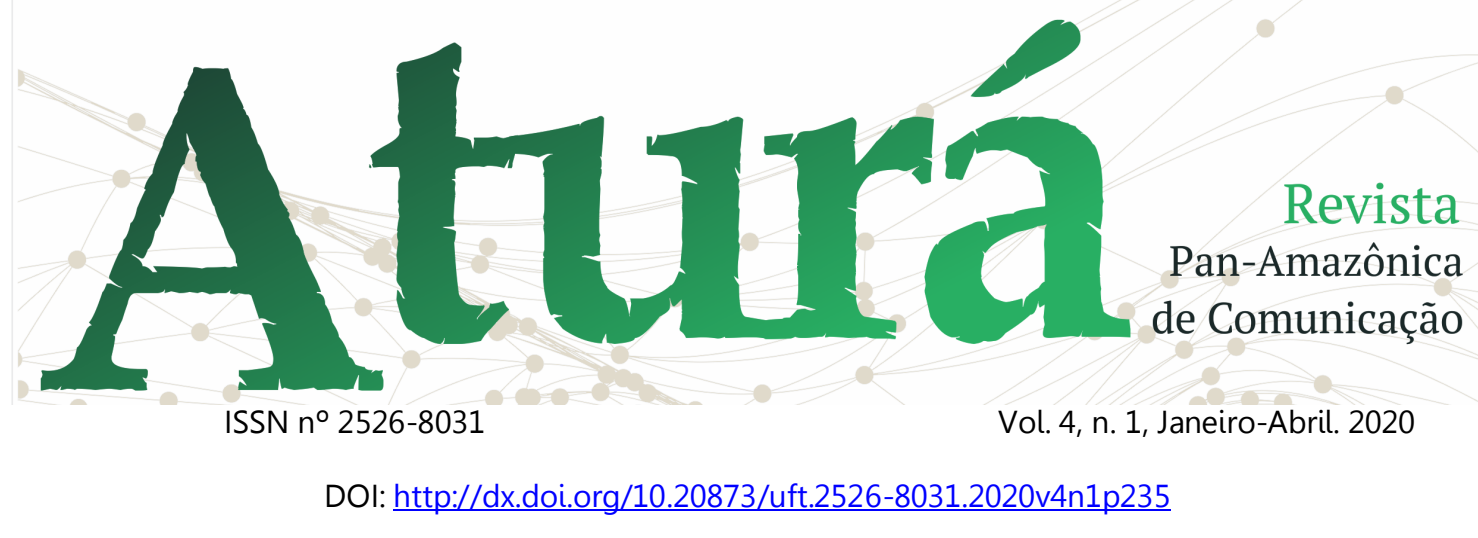

lenciamento à imprensa, será esperar que a Hidra de Lerna desperte por meio de atentados à população e aos Aparelhos Repressivos do Estado com incêndios a ônibus, fechamento de escolas e do comércio local, conforme veiculado pela imprensa em vinte e um de junho de dois mil e dezoito: "Micro-ônibus é incendiado por criminosos na região sul de Palmas." (Disponível em: < https://g1.globo.com/to/tocantins/noticia/onibus-e-incendiado-por-criminosos-na-regiao-sul-de-palmas.ghtml>.

Acesso em: 05 dez 2019.); isso sem falar nos crimes mediante terror quando da Casa de Prisão Provisória de Palmas vierem às determinações transcritas em outros salves que as duas organizações voltaram a se unir contra o Estado e os ideais do Poder Paralelo deverão ser respeitados, caso contrário vidas inocentes poderão ser ceifadas pela desídia do Estado Democrático de Direito.

E a Análise do Discurso é o elemento primordial para em conjunto com o sistema de inteligência dos Aparelhos Repressivos de Estado sirva à comunidade e contribua para a preservação da paz social, sendo o discurso do poder paralelo a materialização das relações de poder.

\section{REFERÊNCIAS}

ALTHUSSER, Louis. Ideologia e Aparelhos Ideológicos do Estado. Lisboa, Portugal: Martins Fontes, 1970. $121 \mathrm{p}$.

BRANDÃO, Helena H. Nagamine. Introdução à análise do discurso. $3^{\mathrm{a}}$ Ed. Campinas, SP: Editora da Unicamp, 2017. 120 p.

BRASIL. [Constituição (1988)]. Constituição da República Federativa do Brasil de 1988. Brasília, DF: Presidência da República, [2016]. Disponível em: http://www.planalto.gov.br/ccivil_03/Constituicao/ Constituiçao.htm. Acesso em: 03 dez. 2019.

CÉSPEDES, Lívia; ROCHA, Fabiana Dias da (Colaboradores). VADE MECUM SARAIVA. $27^{\mathrm{a}} \mathrm{Ed}$. atual e ampl.- São Paulo: Saraiva Educação, 2019.

FOUCAULT, Michel. Em defesa da sociedade. Tradução Maria Ermantina Galvão. $2^{\text {a }}$ Ed. São Paulo: Editora WMF Martins Fontes, 2010. 274 p. Tradução de: Il faut défendre la société.

Microfísica do Poder. Org. e tradução Roberto Machado. 22 ${ }^{\mathrm{a}}$ Ed. Rio de Janeiro: Edições Graal, 2006. 296 p. Tradução de: Microfísica del potere.

são. Tradução Raquel

Vigiar e punir: nascimento da pri-

Ramalhete. 20a Ed. Rio de Janeiro: Vozes, 1987. 297 p. Tradução de: Regarder et Punir. 


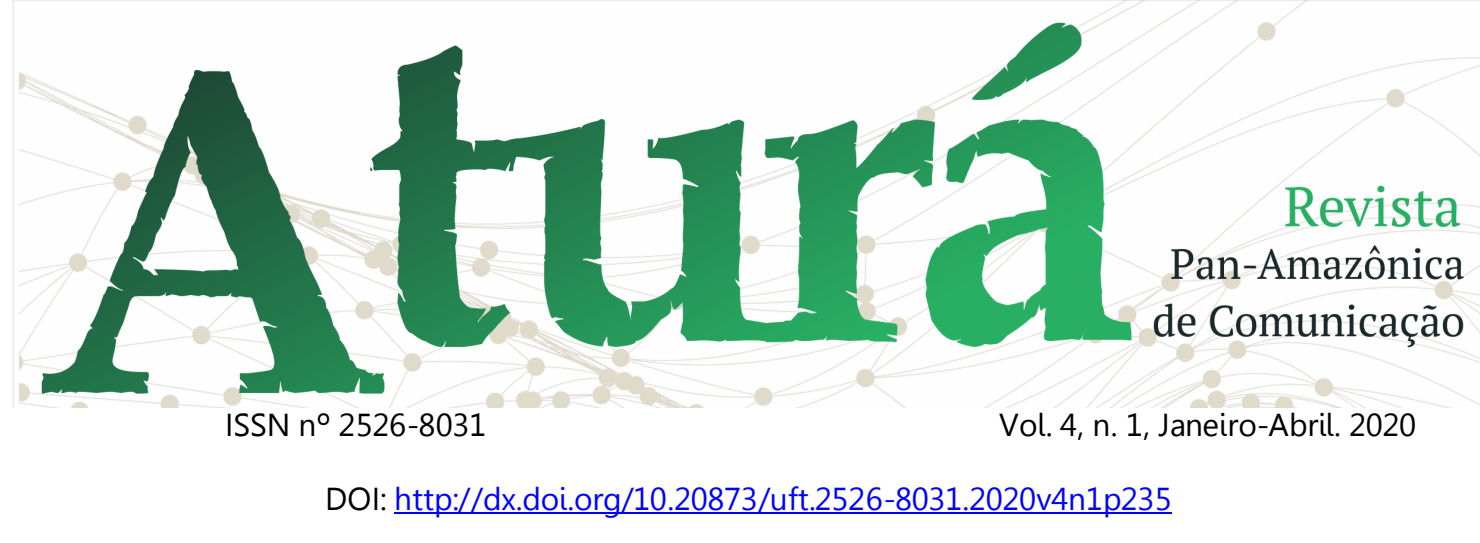

G1 TOCANTINS, Palmas, 21/06/2018 23h03.

(Disponível em: < https://g1.globo.com/to/to-

cantins/noticia/onibus-e-incendiado-por-cri-

minosos-na-regiao-sul-de-palmas.ghtml $>$.

Acesso em: 05 dez 2019.)

MAINGUENEAU, Dominique. Discurso e análise do discurso. Tradução de Sírio Possenti. São Paulo: Parábola Editorial, 2015. 192 p. Tradução de: Discours et analyse du discours

MANSO, Bruno Paes; DIAS, Camila Nunes. A GUERRA: A ascensão do PCC e o mundo do crime no Brasil. São Paulo: Todavia, 2019. 344 p.

MARQUES, Wellison. Metodologia de pesquisa em Análise de Discurso face aos novos suportes midiáticos. DOMÍNIOS DE LINGU@GEM. Revista Eletrônica de Linguística ( http://www.seer.ufu.br/index.php/dominiosdelinguagem ). Volume $5,-n^{\circ} 1-1^{\circ}$ Semestre 2011.

ORLANDI, Eni P. Análise de Discurso: princípios e procedimentos. $7^{a} \mathrm{Ed}$, Campinas, São Paulo: Pontes, 2007. 100 p.

SOARES, Thiago Barbosa. Percurso Linguístico: conceitos, críticas e apontamentos. CampinasSP: Pontes Editores, 2018. 208 p. 